\title{
TRAITS INHERITANCE AND CLUSTER ANALYSIS OF F1 PLANTS OBTAINED ON THE BASIS OF HYBRIDIZATION OF G.BARBADENSE L.VARIETIES AND LINES
}

\author{
SH.A. Samanov \\ Science Academy of the Republic of Uzbekistan, Institute of Genetics and experimental biology of \\ plants, Tashkent region, Kibray district, Yukory-Yuz makhalla,
}

\author{
B.KH. Amanov \\ Science Academy of the Republic of Uzbekistan, Institute of Genetics and experimental biology of \\ plants, Tashkent region, Kibray district, Yukory-Yuz makhalla,
}

Article DOI: https://doi.org/10.36713/epra4541

\begin{abstract}
This article outlines the results of analysis of farm-valuable traits inheritance of $F_{1}$ plants obtained on the basis of hybridization of varieties and lines belong to G.barbadense L.cotton plant species. Dominating level and its inheritance was determined to be under positive and medium negative, dominant and super dominant forms according to the studied cotton weight, fiber length and yield, weight of 1000 cotton seeds in one cotton boll. It is required to continue genetic-breeding research work on next generations for maintaining positive heterosis status achieved at $F_{1}$ generation. In order to identify the interrelation of varieties by their farm-valuable traits through analyzing group division of clusters in which varieties are combined, a four-cluster type analysis was found to be the most favorable for an effective work.

KEYWORDS: species, variety, line, hybridization,inheritance, cluster,generation, cotton weight, fiber length and yield, weight of 1000 cotton seeds in one cotton boll, dominating level, super dominant, heterosis, negative heterosis.
\end{abstract}

\section{INTRODUCTION}

Cotton plant varieties that belong to G.barbadense L.speceis are known to be higher hot requiring by their biological attributes, and they are grown in some fields of southern regions. The introduction of fine-fiber cotton in the country will bring great benefits to the state economy. One of the main disadvantages of fine-fiber cotton varieties is their low yield and late maturation. One of the main indicators of cotton productivity is fiber yield, on the base of the study of the inheritance nature and modification it has been determined that the trait depends on the parental genotypes and it is possible to achieve a large-scale transgression in fiber yield and quality by hybridization of different species. In order to implement this, creation of precocious varieties with best fiber quality and high yield and expanding crop lands of cotton plant varieties of G.barbadense L. species play an important role [5, 7, $9,11]$.

Plants isolated from the higher generation of backcross hybrid populations that obtained by $\begin{array}{llllll}\text { crossing (OT-817 } & \mathrm{x} & \text { ¡010972) } & \mathrm{x} & \mathrm{T}-817 & \mathrm{a}\end{array}$ geographically distant 010972 sample of G.barbadense L. species with the T-817 line of finefiber cotton and inheritance of farm-valuable traits of the plants of this group with large cotton bolls (larger than 4,2 g), their modification and correlation among them have been studied. In higher generation hybrid plants, it has been proven that strong negative correlations between fiber yield and fiber length, 


\section{EPRA International Journal of Research and Development (IJRD)}

fiber yield and weight of 1000 cotton seeds can be altered in a positive way [3].

A lot of fine-fiber varieties have been developed in the Republic of Uzbekistan since today including Termiz-7, Termiz-8, Termiz-14, Termiz-15 and Termiz-31. Later other fine-fiber varieties (C6029, C-6030, C-6032, C-6037, C-6040, C-6042, Karshi-8, Karshi-9, Surkhon-2, Surkhon-3, Surkhon5, Surkhon-7, Surkhon-9, Surkhon-14, Surkhon-16, Surkhon-18, Surkhon-100, Surkhon-101, Surkhon102, Surkhon-103) have been created and regionized. The growing demand for the purchase of high quality fiber in the world cotton market in recent years is closely connected with the need to create I-a, I-b, I, II types of fine fiber varieties [8].

Due to a sharp rise in temperature and frequent hot winds in Surkhandarya and Kashkadarya regions during the growing season of cotton plant, the loss of yield elements of medium-fiber cotton varieties has been observed. Therefore, in the southern regions it is recommended to plant finefiber varieties of cotton. In particular, the information about the farm-valuable traits of Termiz-202, Termiz-208 varieties has been presented. Also, Termiz-202 and Termiz-208 varieties have been reported to have high opening rates of bolls [4].

Another method of multidimensional statistics is cluster analysis. The cluster analysis method is based on measuring the Euclidean distance between points (varieties) in a multidimensional space as a measure of genetic divergence to distinguish genetically close groups of varieties. Tryon was the first to use cluster analysis term in sociology and described this method. Cluster analysis basis is consisted of close or similar divisions - clusters of a number of objects and traits. Clustering methods can be used in even the simplest grouping operations. The best aspect of this method is that it can be used to separate objects into a whole set of characters or traits. In addition, cluster analysis, unlike most mathematical and statistical methods, places no restrictions on the objects under consideration and allows the processing of different amounts of data of different nature.

As N.I. Vavilov noted, sometimes there are different genotypes under the similarity of varieties by appearance [6]. One-sided selection of such varieties leads to diversification of population biotypes and a decrease in varietal indications. This case raises the questions: how can genotypes be grouped? How to determine which of them belongs to this variety on the basis of farm-valuable traits? Clarification of these questions is related to the study of the genetic structure of varieties.

In the correct grouping of genotypes according to their genetic proximity, it is necessary to determine the number of clusters sufficient to meet the goal set for the classification of samples. In his research, R. Abidov [1, 2] used the cluster method to determine the similarity of cotton species in terms of protein components. The author acknowledged that as a result of the six-cluster analysis, natural allotetraploid species and representatives of the $\mathrm{D}$ genome group have a relatively close genetic relationship. This is evidenced by the fact that they are combined into a single cluster. Studies have shown that the easily soluble protein components of seeds are genomically specific, which makes it possible to determine the relative proximity of cotton species.

Several measures have been conducted on the use of factor and cluster analysis methods in local varieties and lines. The author used k-cluster and hierarchical analysis programs to determine the genotypic diversity of the species and lines studied in his research. Using Euclidean distance as a measure of genetic proximity and Word method as a method of aggregation, the author identified indicators on a number of traits to determine the genotypic composition of the S-6770 variety population of cotton plant. As a result, he distinguished 5 groups of clusters that differ from the original population in the set of trait and retain their characteristics in generations. The first cluster consisted of plants with small bolls and the lowest yields, low weight of 1000 seeds and fiber index. The second cluster consisted of large-boll plants with higher yields per plant than the population average index. The third group consisted of plants with the lowest fiber yield but the seeds were relatively large, the fourth group consisted of plants with small and less bolls, 1000 seeds with low weight, the lowest yields and late maturation. In the fifth cluster, the number of plants was the smallest, but with the most number and largest bolls, and also with higher weight of 1000 seeds [10].

\section{OBJECT AND THE METHODS OF RESEARCH}

The experiments were carried out in extension fields of the laboratory of Cotton systematics and introduction of the Institute of Genetics and experimental biology at the Academy of Sciences of the Republic of Uzbekistan. As an object of the research cultural Termiz-31, Surkhon14, Surkhon-18, Iloton, Angor varieties and lines with large bolls which belong to G.barbadense L. species were chosen.

The following methods were used to conduct the research: simple hybridization, mathematical and cluster analysis. 


\section{RESEARCH RESULTS}

According to the parameters of the initial samples selected for the study it was found out that by the trait of cotton weight of one cotton boll, the largest boll was average 5,9 grams in T-2006 line and the lowest indication by trait was 2.4 grams in cultural Iloton variety (Table 1). 


\section{EPRA International Journal of Research and Development (IJRD)}

Volume: 5 | Issue: 5 | May 2020

- Peer Reviewed Journal

Table-1

Inheritance of farm-valuable traits of initial sources and $F_{1}$ plants obtained by their hybridization

\begin{tabular}{|c|c|c|c|c|c|c|c|c|}
\hline $\begin{array}{l}\text { Initial sources and their } F_{1} \text { hybrid } \\
\text { combinations }\end{array}$ & $\begin{array}{l}\text { Cotton weight of } \\
\text { one boll, gr }\end{array}$ & hp & Fiber length & hp & Fiber yield & hp & $\begin{array}{l}\text { Weight of } \\
1000 \text { seeds }\end{array}$ & hp \\
\hline Surkhon-14 & $3,2 \pm 0,13$ & - & $40,3 \pm 0,26$ & - & $34,0 \pm 0,03$ & - & $119,3 \pm 1,1$ & - \\
\hline Surkhon -18 & $2,7 \pm 0,08$ & - & $40,3 \pm 0,18$ & - & $37,3 \pm 0,49$ & - & $107,95 \pm 1,2$ & - \\
\hline Iloton & $2,4 \pm 0,19$ & - & $39,5 \pm 0,13$ & - & $34,0 \pm 0,38$ & - & $104,0 \pm 1,4$ & - \\
\hline Termiz-31 & $3,2 \pm 0,20$ & - & $39,4 \pm 0,31$ & - & $36,5 \pm 0,53$ & - & $123,6 \pm 1,8$ & - \\
\hline Angor & $4,8 \pm 0,12$ & - & $40,2 \pm 0,17$ & - & $36,5 \pm 0,35$ & - & $141,4 \pm 1,8$ & - \\
\hline $\mathrm{T}-1985$ & $5,7 \pm 0,06$ & - & $40,2 \pm 0,16$ & - & $35,3 \pm 1,03$ & - & $143,7 \pm 2,3$ & - \\
\hline T-2006 & $5,9 \pm 0,38$ & - & $40,3 \pm 0,18$ & - & $34,8 \pm 0,52$ & - & $146,0 \pm 1,7$ & - \\
\hline T-2017 & $5,6 \pm 0,20$ & - & $40,7 \pm 0,24$ & - & $34,6 \pm 0,29$ & - & $139,8 \pm 1,8$ & - \\
\hline T-2017-2 & $5,3 \pm 0,20$ & - & $39,3 \pm 0,26$ & - & $35,9 \pm 0,40$ & - & $134,1 \pm 1,9$ & - \\
\hline$F_{1} T-1985 \times$ Surkhon-14 & $4,4 \pm 0,07$ & $-0,04$ & $40,0 \pm 0,04$ & $-5,0$ & $36,9 \pm 0,68$ & 3,4 & $102,6 \pm 0,08$ & $-2,3$ \\
\hline$F_{1}$ Surkhon-14 x Angor & $4,2 \pm 0,15$ & 0,2 & $39,0 \pm 0,04$ & $-25,0$ & $36,4 \pm 0,36$ & 0,9 & $105,4 \pm 0,06$ & $-1,2$ \\
\hline$F_{1}$ Surkhon-14 x Iloton & $3,8 \pm 0,06$ & 2,5 & $38,8 \pm 0,02$ & $-2,7$ & $36,4 \pm 0,58$ & 2,4 & $120,8 \pm 0,08$ & 1,1 \\
\hline F1Termiz-31 x Angor & $4,2 \pm 0,15$ & 0,2 & $38,3 \pm 0,03$ & $-1,9$ & $37,4 \pm 0,34$ & 0,9 & $108,5 \pm 0,07$ & $-2,6$ \\
\hline$F_{1}$ Angor x Surkhon-14 & $4,2 \pm 0,07$ & 0,2 & $38,5 \pm 0,03$ & $-0,3$ & $36,4 \pm 0,31$ & 0,9 & $107,1 \pm 0,10$ & $-2,1$ \\
\hline$F_{1} T-2017-2$ x Iloton & $4,3 \pm 0,07$ & 0,3 & $38,7 \pm 0,02$ & $-7,0$ & $30,5 \pm 0,51$ & $-3,0$ & $116,9 \pm 0,09$ & $-0,14$ \\
\hline$F_{1} T-2017 x$ Surkhon-14 & $3,9 \pm 0,07$ & $-0,4$ & $37,6 \pm 0,02$ & $-14,5$ & $35,3 \pm 1,20$ & $-3,3$ & $98,4 \pm 0,14$ & $-3,0$ \\
\hline$F_{1}$ Surkhon-18 x Iloton & $3,2 \pm 0,09$ & 4,3 & $38,0 \pm 0,04$ & $-4,7$ & $34,2 \pm 0,70$ & $-0,8$ & $79,3 \pm 0,48$ & $-9,0$ \\
\hline$F_{1}$ Angor x Iloton & $4,1 \pm 0,11$ & 0,4 & $40,2 \pm 0,03$ & 1,0 & $33,7 \pm 0,13$ & $-1,2$ & $114,4 \pm 0,10$ & $-0,43$ \\
\hline$F_{1} T-2017$ x Iloton & $4,0 \pm 0,10$ & 1,6 & $39,2 \pm 0,03$ & $-1,1$ & $35,5 \pm 0,59$ & 4,0 & $109,8 \pm 0,05$ & $-0,67$ \\
\hline$F_{1} T-2017-2 \times$ Surkhon-14 & $3,9 \pm 0,03$ & $-0,3$ & $40,3 \pm 0,02$ & 1,0 & $36,8 \pm 1,83$ & 1,9 & $105 \pm 0,14$ & $-2,93$ \\
\hline$F_{1}$ Angor x Surkhon-14 & $4,3 \pm 0,08$ & 0,3 & $38,2 \pm 0,08$ & $-41,0$ & $35,3 \pm 0,57$ & 0,04 & $81,3 \pm 0,17$ & $-4,4$ \\
\hline$F_{1} T-2006 \times$ Iloton & $4,6 \pm 0,05$ & 0,2 & $39,8 \pm 0,03$ & $-0,2$ & $34,3 \pm 0,28$ & $-0,2$ & $89,4 \pm 0,14$ & $-1,69$ \\
\hline$F_{1} T-1985 \times$ Iloton & $4,0 \pm 0,08$ & $-0,03$ & $38,6 \pm 0,03$ & $-3,5$ & $32,5 \pm 1,13$ & $-3,3$ & $108,2 \pm 0,04$ & $-0,78$ \\
\hline
\end{tabular}




\section{EPRA International Journal of Research and Development (IJRD)}

Being one of farm-valuable traits of cotton, the weight of cotton in one boll constituted average 3,2-4,6 grams in $F_{1}$ plants obtained by hybridization of varieties and lines of cotton, and this result showed that the inheritance of this trait varied. A strong heterosis condition was observed in the plants obtained by crossing two plant forms that had less differed cotton weight in one boll, while in hybrids obtained from hybridization of the forms with large and small cotton bolls, the weight of cotton in one boll was observed to be in the positive and negative intermediate state of heredity. For example, in $F_{1}$ Surkhon-18 x Iloton combination, the average weight of cotton in one boll was 3,2 grams, while in super dominant (hp $=4,3)$ Surkhon-14 x Angor combination, this trait was defined to be inherited in positive intermediate state $(\mathrm{hp}=0,2)$.

As a result of the study of the fiber length trait of the fine-fiber varieties and lines selected as the primary source, the indication was $39,3-40,7 \mathrm{~mm}$.

In $F_{1}$ plants obtained as a result of hybridization, effective results were observed on the trait of fiber length $(37,6-40,0 \mathrm{~mm})$, the best index on this trait was recorded in the combination $\mathrm{F}_{1} \mathrm{~T}-2017-2 \mathrm{x}$ Surkhon-14 to be average $40,3 \mathrm{~mm}$, in the dominant position of the trait $(\mathrm{hp}=1,0)$ the lowest index in terms of fiber length constituted $37,6 \mathrm{~mm}$ in $\mathrm{F}_{1} \mathrm{~T}-2017 \mathrm{x}$ Surkhon-14 combination, and the coefficient of inheritance was observed to be negative, occurring under extreme dominance $(\mathrm{hp}=-14,5)$.

The analysis of the results of the study shows that (Table 1) the selected initial sources have different fiber yield trait, a high rate was in Surkhon-18, i.e $37,3 \%$, while in Surkhon-14 and Iloton varieties this indication was equal to $34,0 \%$.

The fiber yield in $F_{1}$ plants was average 30,5$37,4 \%$, the highest index on this trait was recorded in combination $\mathrm{F}_{1}$ Termiz-31 $\mathrm{x}$ Angor, that is an average of $37,3 \%$, the lowest index in the combination T-2017$2 \times$ Iloton constituted $30,5 \%$. In $\mathrm{F}_{1}$ hybrids, fiber yield trait was inherited in the negative and positive intermediate, dominant and super dominant states.

Experimental data showed that the initial source samples involved in the hybridization on 1000 seeds weight trait differed from each other. By the trait of 1000 seeds weight in the T-2006 line the largest seed showed $146,0 \mathrm{~g}$, while in Iloton variety the average weight of 1000 seeds was found to be average, that is the indication of the trait was 104,0 $\mathrm{g}$ (Table 1).

In $F_{1}$ plants obtained as a result of crossing, different results were observed for the weight of 1000 seeds, weight varied from 79,3 to 120,8 grams. The best indication on this trait was recorded in $\mathrm{F}_{1}$ Surkhon$14 \mathrm{x}$ Iloton combination - the average large seed weighed 120,8 grams, and the coefficient of inheritance was observed in the case of positive super dominance (hp $=1,1$ ), on the trait of 1000 seeds weight a small seed indication was determined to be average 79,3 grams in $\mathrm{F}_{1}$ Surkhon-18 $\mathrm{x}$ Iloton combination and the coefficient of inheritance was negative in super dominance $(\mathrm{hp}=-9,0)$

For the cluster analysis, 5 cultivars belonging to the G.barbadense L. species and 4 lines with large bolls (Table 1) were used as initial data. These parameters of the varieties were determined in laboratory and field conditions. Our goal is to determine the degree of diversity of these varieties according to their farm-valuable traits and to combine them by their relative proximity, and the cluster analysis method was used to achieve this goal. This method is based on determining the Euclidean distance between varieties, as mentioned in the previous sections, and this distance is measured not in plane, but in multidimensional space.

When analyzing the division of the combined clusters of varieties into groups, we found that the 4cluster analysis was the most moderate to determine the proximity of the varieties in terms of farm-valuable traits (Table 2).

The first cluster included Surkhon-14 and Iloton varieties, which mainly formed the plants with the lowest fiber yield $(34,0 \%)$. In the varieties included in this cluster, the weight of cotton in one boll was $2,8 \mathrm{~g}$, the fiber length was $39,9 \mathrm{~mm}$ and the weight of 1000 seeds was $111,6 \mathrm{~g}$. It was identified that all farm-valuable traits of the varieties included in this cluster had low index.

The second cluster consisted of varieties with the highest fiber length of $40,3 \mathrm{~mm}$ average and fiber yield of $37,3 \mathrm{~mm}$, and the weight of cotton in one boll was $2,7 \mathrm{~g}$, the weight of 1000 seeds was recorded as 107,9 g. In Termiz-31, Surkhon-18 varieties and T-2017-2 lines that included in this cluster, the fiber yield and fiber length index were higher than in the varieties of other clusters, and these varieties can be used to improve the indicators of this trait.

The third group included the Angor variety, which had the highest rate of farm-valuable traits. The weight of cotton in one boll of this variety was equal to $4,2 \mathrm{~g}$, while fiber length made $39,3 \mathrm{~mm}$, fiber yield $36,2 \mathrm{~mm}$ and weight of 1000 seeds was 128,8 grams.

The fourth group constituted T-1985, T2006, and T-2017 lines, and the varieties combined in this cluster presented mainly the highest index of cotton weight in one boll, fiber length, and the weight of 1000 cotton seeds. These lines are important in creating fine-fiber cotton varieties with high fiber length and high yield. 


\section{EPRA International Journal of Research and Development (IJRD)}

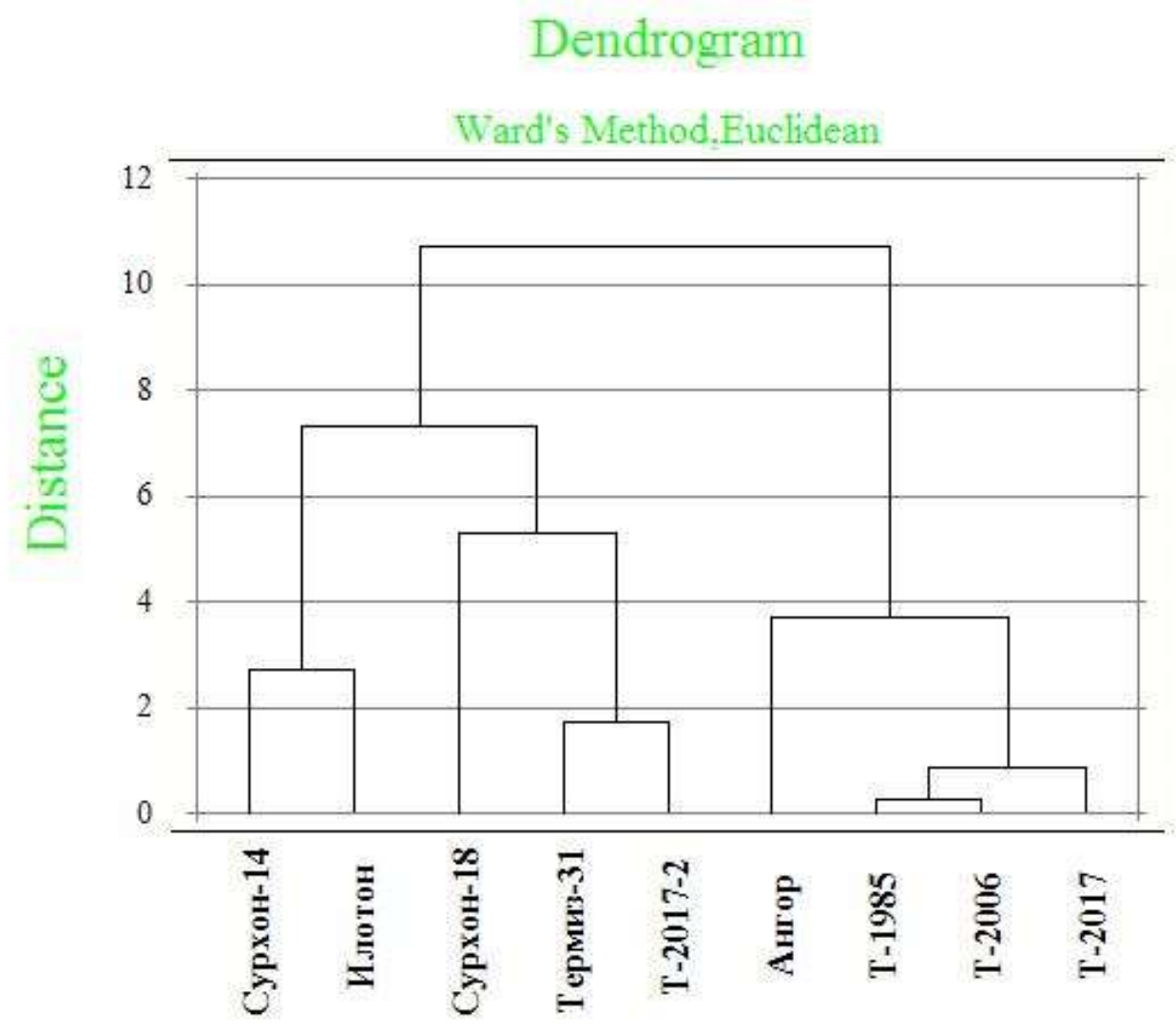

Table-2

Average parameters of cluster divisions according to farm-valuable traits

\begin{tabular}{|c|c|c|c|c|}
\hline $\begin{array}{c}\text { Cluster } \\
\text { number }\end{array}$ & $\begin{array}{c}\text { Cotton weight in one } \\
\text { boll, } \mathbf{g}\end{array}$ & Fiber length & Fiber yield & $\begin{array}{c}\text { Weight of 1000 } \\
\text { seeds }\end{array}$ \\
\hline 1 & 2,8 & 39,9 & 34,0 & 111,65 \\
\hline 2 & 2,7 & 40,3 & 37,3 & 107,9 \\
\hline 3 & 4,25 & 39,35 & 36,2 & 128,85 \\
\hline 4 & 5,5 & 40,35 & 35,2 & 142,72 \\
\hline
\end{tabular}

\section{CONCLUSION}

Analysis of the obtained results showed that the inheritance of farm-valuable traits in $\mathrm{F}_{1}$ plants obtained on the basis of hybridization of varieties and lines belonging to the G.barbadense L. species had been analyzed thoroughly. It was determined that the dominating level in accordance with cotton weight, fiber length, fiber yield, weight of 1000 seeds in one boll was found to be inherited in the positive and negative intermediate, dominant and super dominant state. In order to maintain the positive heterosis that was achieved in $F_{1}$ generation, it is necessary to continue genetic selection research work in the next generations. When analyzing the divisions of the clusters in which the varieties combined, a 4-cluster analysis was found to be the most moderate to determine the proximity of the varieties in terms of their farm-valuable traits.

\section{REFERENCES}

1. Abidov $R$. Analysis of heterogeneity of seed albumen in different tetraploid forms of cotton plant. // Uzbekistan biology journal. -Tashkent, 1999. -№2. -pp.57-59.

2. Abidov R. Polymorphism of albumen and its genetic stipulation in originally different types and varieties of cotton plant. Abst.of diss.on doct.biol.sciences- T.: 2001.p -39.

3. Abdiyev F.R. Preparation of initial material for practical selection from higher generation hybrids belonging to G.barbadense L. specis. Abstr.cand.agri.scien. Tashkent. 2011. pp.1819. 


\section{EPRA International Journal of Research and Development (IJRD)

Akhmedov J.Kh., Choriyeva Kh. Advantages of fine-fiber cotton plant.// Agriculture journal. Tashkent. 2018. -№9.p - 31.

5. Bakhshy M.A., Khalmanov B.A., Toshpulaov Sh.K. Efficacy of different doses of gamma rays for the improvement of precocity of cotton plant belonging to G.barbadenseL.species//From the collections "Selection and seed-breeding of cotton and lucerne" devoted to the 120th anniversary of the birthday of G.S.Zaysev, to the 100th anniversary of the birthday of A.D. Dadabayev, L.G. Arutyunova and G.Ya. Gubanov. - Tashkent. 2009. - pp. 245-250.

6. Vavilov N.I. The law of homologous lines in heritable variability. -Leningrad. 1987. p-131.

7. Iksanov M., Egamberdiyev A., Khalmanov B. Fiber - a main production of cotton growing// Agriculture journal of Uzbekistan.- Tashkent. 2006. - №6. -pp. 11-12.

8. Nazarov R., Avtonomov V., Akhmedov J., Kurbanov A. Selection of fine-fiber varieties of cotton plant in Uzbekistan// 'Agro ilm' scientific appendix of Agriculture journal of Uzbekistan. -Tashkent. 2017. - №1. - pp. 5-7.

9. $\quad$ Chorshanbiyev N.E. Inheritance and variability of morphological farm traits in F1-F2 plants of local cotton plant varieties belonging to G.barbadense L.species. Abst.diss..doct.biol.scien. Tashkent. 2018. - pp. 13-15.

10. Shadraimov R.Ye. Genetic structure of varieties and lines of cotton plant by their traits and modification selection.//Abstr..cand.agr.scien.-Tashkent, 2006. $p-20$.

11. Abdullayev A.A., Abdullayev A.A., Salakhutdinov I.B., Rizaeva S.M., Kuryazov Z.B., Ernazarova D.K., Abdurakhmonov I.Y. Cotton Germplasm. Collection of Uzbekistan// The Asian and Australian Journal of Plant Science and Biotechnology . 2013. - №2. - P. 15 . 